УДК 330.8(47)

ББК 65.02(2)

DOI $\underline{10.17150 / 2308-2588.2016 .17(4) .699-720}$

Д. Я. Майдачевский

Байкальский государственный университет, г. Иркутск, Российская Федерация

\title{
ЗЕМСКАЯ СТАТИСТИКА КАК ЭКОНОМИКА: К ИСТОРИИ КАЧЕСТВЕННЫХ ЭКОНОМИЧЕСКИХ ИССЛЕДОВАНИЙ В РОССИИ
}

Аннотация. Статья посвящена изучению исследовательских практик русских земских статистиков. Предмету тем более актуальному, что качественная междисциплинарная методология - способы исследовательского взаимодействия с людьми и прямого наблюдения реальности, использовавшиеся последними, перестали рассматриваться в качестве методов, являющихся неотъемлемой принадлежностью инструментария экономистов. Научная новизна работы определяется состоянием историографии экономической науки, господство в которой историко-мыслительного подхода закрепило ошибочный ракурс видения земской статистики лишь как этапа или стадии в развитии статистической науки. Между тем, земско-статистические работы сопровождались качественными экономическими исследованиями. Их междисциплинарная по своему характеру методология была неоправданно сведена к вспомогательному элементу методологии статистической, а сами они стали рассматриваться результатом «увлечений» земской статистики, выходящих за пределы непосредственной ее задачи - массового аналитического исследования крестьянского хозяйства при помощи средних и относительных величин.

Ключевые слова. Историография экономической науки, земская статистика, качественные исследования в экономике, А. А. Кауфман, наблюдения, опрос, этнографическая экономика. 


\title{
D. Ya. Maidachevsky \\ Baikal State University, \\ Irkutsk, Russian Federation \\ ZEMSTVO STATISTICS AS ECONOMICS:
HISTORY OF QUALITATIVE ECONOMIC RESEARCHES IN RUSSIA
}

\begin{abstract}
The article addresses the study of Russian zemstvo statisticians' research practice. Research significance of the subject is determined by the fact that the qualitative interdisciplinary methodology as the way of zemstvo statisticians' research interaction with people and direct observation of the economic reality is ceased considering as the inevitable part of economists' research toolset. The scientific originality of the project is specified by the conditions of historiography of economics (the domination of «history-of-thought» approach settled the mistaken comprehension of the zemstvo statistics just as the stage of Statistic Science development). Meanwhile, the zemstvo statistics works came amid the qualitative economic research, which the interdisciplinary methodology was unreasonably narrowed down to the statistics methodology secondary element, and these methods were seen as a result of unnecessary overdevelopment of zemstvo statistics in compare with its basic aim to provide mass analytical research of peasants' households with the help of average and relative values.

Keywords. Historiography of economics, zemstvo statistics, qualitative researches in economics, A. A. Kaufman, observation, survey techniques, ethnographical economics.
\end{abstract}

Обращение к возможно ключевому отрезку истории отечественной экономической науки - ответ на очевидный и признаваемый едва ли не единодушно методологический кризис научного экономического знания. Заметим, кризис, ставший во многом результатом свершившейся в недавнем прошлом эконометрической революции, вследствие которой прогресс и познаватель- 
ные возможности науки стали связываться едва ли не исключительно с совершенствованием экономико-математического аналитического аппарата. Не будет надуманной аналогия между современным и методологическим кризисом классической политической экономии, на фоне которого шло в пореформенный период истории становление отечественной экономической науки, качественная междисциплинарная методология которой стала на него ответом. Исторический анализ последней и присущих ей приемов изучения экономической реальности, традиции коих были утрачены в последующих не только «статистических», «эконометрических», но и «идеологических» революциях, может оказаться значимым с точки зрения возможности возрождения и развития отечественной экономической науки. Стать ответом уже на современный методологический кризис экономической науки, избежать которого отечественная наука, слепо следующая за западной, не в состоянии. Наконец, положить начало пересмотру онтологических (парадигмальных) оснований современной экономической науки, ее возвращению в лоно наук об обществе.

Качественные исследования в экономике (не говоря уже об осуществлявшихся русскими земскими статистиками), не были предметом самостоятельного внимания истории экономической науки. Да и сами качественные исследования трактовались скорее как «качественный анализ данных», чаще всего статистических (наборы которых отождествлялись с методом наблюдений), а не рассматривались в качестве самостоятельного подхода к производству знания. Лишь последние годы ознаменовались пробуждением интереса к истории приемов качественного исследования в экономике, свидетельством чему стали конференция «История наблюдения в экономической науке» ("А history of observation in economics"), проведенная Цен2016. T. 17, № 4. C. $699-720$ 
тром истории политической экономии Duke University в 2011 г., а также изданные в качестве книжного приложения к издаваемому этим университетом журналу «History of Political Economy» ее материалы ${ }^{1}$.

Импульс этих событий докатился и до отечественной историко-экономической науки в виде публикации перевода одной из статей сборника [15], переводчик которой В. М. Ефимов может считаться одним из немногих пропагандистов качественной экономической методологии (дискурсивной, интерпретативной). А также статьи британского историка русской экономической мысли В. Барнетта [26], знакомящей российского читателя с основными положениями опубликованной в том же сборнике более ранней его работы [25]. Статья эта, посвященная, в том числе и земской статистике, отказывает последней в какой-либо оригинальности, полагая «уникальными» скорее «российские учреждения», нежели методы наблюдения, им присущие. Называя «беспрецедентной» массу сырых фактов, добытых земской статистикой, она видит качественные экономические исследования, ею осуществлявшиеся, частью более широкой континентальной традиции исторической школы, подходы которой не уступали своих позиций в отечественной науке вплоть до 1917 г.

Хотя датой рождения земской статистики можно считать 1864 г., положивший начало созданию губернских и уездных земских учреждений, включая статистические бюро, призванные удовлетворить потребность в материалах для правильной раскладки земских повинностей, деятельность последних, развернулась уже в следующем десятилетии. При этом практически сразу выйдя за узкие рамки земельно-оценочных работ и будучи нацелена, как свидетельствуют сами земские

${ }^{1}$ В открывавшей книжку статье редакторов сборника подчеркивалось, что наблюдение как деятельность не следует отождествлять с определением количества (квантификацией), точно также как и результат наблюдения - с мерой наблюдаемого [27, p. 1]. 
статистики, на «общеэкономическое изучение народного быта» [14, с. 423], проведение местных исследований хозяйственных отношений. В числе первоочередных интересов земской статистики оказались вопросы форм владения и пользования землей, или как более широко, акцентируя внимание на институциональном аспекте, определяет этот ее интерес В. Барнетт «организационные формы экономики», имея в виду прежде всего общину (но также и артель, и кустарные промыслы), ставшую приоритетным предметом статистико-монографического описания [26, с. 98-99].

Историко-мыслительный подход в историографии экономической науки [10, с. 47-88], выводящий за рамки своего рассмотрения огромный массив отечественной статистической литературы, объясняет появление последней влиянием «младшей» немецкой исторической школы, сформировавшей образ экономической науки, основывающейся на индуктивном методе [22, с. 223]. Думается, однако, что было бы куда более продуктивным искать корни земской статистики, по крайней мере «нарративной» ее составляющей, в «описательной статистике» последней трети XVIII - первой половины XIX в. (именуемой нередко политико-экономическим в ней направлением), в этом порождении и части немецкого же «государствоведения». В направлении, по словам В. В. Святловского, полезном «при наличности большого числа исследователей, при систематической и обширной постановке сбора первичного материала, при наличности высоко поставленного одухотворяющего работу конечного идеала» $[19, \text { с. 170 }]^{2}$.

Для того, чтобы из «описательной статистики» как знания для государства, явилась статистика уже как

2 О том, что земская статистика продолжает «общегосударственное дело», начатое деятелями «описательного направления», применяя свои методы к «более детальному и постоянному исследованию народной жизни», отмечали и представители земской статистики и историки последней [18, с. 17]. 
часть «народоведения», необходимо отнюдь не изменение формы организации результатов наблюдений (господство «табличного» или «численного» в ней направления), а появление самого объекта этих наблюдений - общества и, соответственно, экономики. Как справедливо заметил в свое время П. Розанваллон, «невозможно понимать становление экономической науки как медленное созревание концептов, которые постепенно формулировались и совершенствовались. Ее развитие также связано с природой отношений между обществом и государством» [16, с. 150]. Метаморфозы, происходившие со статистикой, поэтому, должны рассматриваться как касающиеся самой экономической науки, а появление земской статистики как появление наряду с государственной экономией еще и народной (национальной) экономии. Тем более, что статистика в этот переходный период начала позиционировать себя в качестве научного метода, пригодного для систематических и аналитических целей, а нередко и в качестве самостоятельной социальной науки, изучающей общественные отношения, в любом случае отделяя себя от дисциплин, просто описывающих явления во времени и пространстве ${ }^{3}$.

С земской статистикой связан, поэтому, не только и не столько переход к новому «практическому» этапу изучения вышеупомянутых «организационных форм» народной экономики, пришедший на смену отвлеченным, «теоретическим» о них дискуссиям, сколько обретение познавательного инструментария, более адекватного изначально поставленной задаче изучения «органического» происхождения тех или иных общественных институтов. «Этнографичность», описатель-

${ }^{3}$ По мнению К. Менгера, выделявшего в структуре экономического знания «историческую статистику» (которую он отделял от статистических данных как всего лишь научного материала), последняя, в отличие от «истории», описывающей движение общества, призвана вскрывать факторы его обусловливающие [11, с. 303-304]. 
ность, познавательного аппарата земской статистики удачно сочеталась с ее аналитическим интересом к возникновению и развитию последних - стремлением установить факторы их обусловливающие. Не будет преувеличением рассматривать земскую статистику в этой ее части как экономическую науку, своеобразную «этнографическую экономику» ${ }^{4}$, опирающуюся на качественную методологию с междисциплинарным применением, лежащую в основании используемого ею научного инструментария.

Рассматривая общину на той или иной ступени ее развития как результат закрепления повторяющихся способов взаимодействий людей, поземельных отношений между ними, данная методология была направлена на выявление каузальных связей: определение причинностей подобных действий и взаимодействий людей, а также причин их изменений посредством, главным образом, соотнесения с действием объективных факторов. Нет, поэтому, ничего удивительного в том, что «этнографическая экономика» - видевшая в статистике не способ «численного описания», а опирающийся на качественную методологию способ научного исследования - взялась за то, чтобы дать ответы на столь долго волновавшие русскую общественную мысль вопросы: как начинается/началось общинное землевладение, через какие этапы проходит/прошло в своем развитии, в каких формах существует/существовало, но главное под влиянием каких объективных факторов складывается/складывалось и развивается/развивалось.

Экономическую науку уже давно не причисляют к числу «полевых» дисциплин: природа и взаимодействие с ней человека исключены из ее научной практики. «[С]ильное нежелание рассматривать данные,

${ }^{4}$ Мы заимствуем удачное, на наш взгляд, выражение М. Саллинза, использованное им для обозначения одного из способов истолкования экономики традиционных обществ на основе этнографии [17, с. 16], и не отождествляющее «этнографическую экономику» с «экономической этнографией» [28].

2016. T. 17, № 4. С. 699-720 
полученные во время “полевых исследований”, - это правило среди экономистов», - констатирует современный методолог экономической науки [12, с. 66]. «Субъективное» восприятие исследователями объекта своего изучения и происходящих с ним изменений было заменено статистикой, в результате чего исследования в экономике стали рассматриваться как носящие «объективный» характер, «статистическими» в научном смысле этого слова, т.е. оперирующими исключительно «численными терминами», прибегающими к формализованным правилам сбора данных и количественным методам их обработки.

Результатами «сближения» экономической науки с естествознанием и, соответственно, «отдаления» от социальных наук, их онтологии, эпистемологии и методологии стали, по справедливому замечанию М. В. Синютина, отказ от «изучения причинности, имеющей онтологическое значение» и, уже как следствие, «утрата онтологических целей исследования и замена их проблемой познавательных средств». Возобладавшее «упрощенное суждение о том, что онтология подразумевает “картину реальной действительности” » привело к переходу от изучения свойств реальности к познанию ее «изображений», к преобладанию и последующему совершенствованию формальных методов изучения, к «эпистемологизации онтологии» [20, с. 126-127].

Указанные процессы не могли не отразиться на историографии экономической науки, одним из проявлений чего стал уже упоминавшийся отказ от рассмотрения огромного массива статистической литературы, вместе с которой из отечественной экономической науки была «выплеснута» земская статистика, целая «эпоха», по словам В. В. Святловского, в ее истории. Последняя стала рассматриваться не иначе как в качестве «школы» или «направления» в статистике, становление и утверждение которой в качестве самостоятельной дисциплины на эту эпоху пришлось. Ее 
экономическая составляющая, «этнографическая экономика», превратилась в не имеющую самостоятельного значения стадию в развитии данной дисциплины. Служащую, в лучшем случае, связующим звеном между описательной статистикой первой половины столетия и подворными переписями и оценочными работами, земскую статистику олицетворяющими.

Между тем, качественные экономические исследования сопровождали земско-статистические обследования, а также выполненные по их образцу земскими же статистиками правительственные хозяйственно-статистические исследования землепользования и крестьянских хозяйств в губерниях и областях Азиатской России, были их частью на протяжении всех этапов существования земской статистики. Их междисциплинарная по своему характеру качественная методология была, однако, неоправданно сведена к вспомогательному элементу статистической методологии («качественная статистика»), а сами они стали рассматриваться результатом «увлечений» земской статистики (а точнее - земских статистиков), выходящих за пределы непосредственной ее задачи - массового аналитического исследования крестьянского хозяйства при помощи средних и относительных величин («количественная статистика»). К тому же результатом, лежащим на обочине магистрального пути развития и статистической науки, стремившейся подвести рациональные, математические основания под выработанные на практике способы работы. В лучшем случае результаты «анкетно-описательных» работ признавались значимыми с «краеведческой» точки зрения, как знакомящие с экономикой местности (и здесь в заблуждение вводило слово «местные» в их названиях или даваемых им характеристиках), своеобразной предтечей, предпосылкой собственно статистических, т. е. количественных ее обследований.

Земско-статистическая практика, упомянутые выше хозяйственно-статистические исследования зем2016. T. 17, № 4. C. 699-720 
лепользования и крестьянских хозяйств в губерниях и областях Азиатской России выдвинули из числа «выучеников земской статистики» - к каковым он себя с гордостью причислял - подлинного лидера указанного научного направления (в той, конечно же, мере, в какой «этнографическая экономика» заслуживает этого статуса) - Александра Аркадьевича Кауфмана (1864-1919). Ход и результаты исследований, осуществленных им в Западной Сибири лично, обобщения таковых, полученных другими исследователями, сопровождались мощной рефлексией относительно использованных качественных приемов и методов исследования. А его нацеленность на установление с помощью качественной методологии «этнографической экономики» не одной только последовательности, но и действующих сил, или причин, возникновения и последующего развития общинно-земельных форм, привела к созданию «причинной теории», пригодной для целей «уразумения» истории аграрных отношений 5 .

Первые полевые исследования, участником которых стал А. А. Кауфман, протекали в 1887-1888 гг. на пространстве Ишимского и Туринского уездов Тобольской губернии. Областью приоритетного и научного его интереса станут формы общинного землевладения и землепользования в Сибири, описания которых займут в итоговых материалах, по существу - научных отчетах, больший, нежели это было принято в работах земских статистиков европейской России, объем, превращаясь фактически в самостоятельные научные монографии, каковые на их основе им и будут составлены. Приемы и методы, вырабатывавшиеся исследователем буквально по ходу работ, получат в увидевших свет материалах весьма примечательную характеристику. Автор подчеркнет «нестрого статистический», или неколичественный, их характер. И не только потому,

${ }^{5}$ Подробнее о проекте «живой истории общины» А. А. Кауфмана см.: [9]. 
что даже собранные статистическим путем (выборочной подворной переписью) цифровые данные играли в работе исключительно иллюстративную роль. За неимением подходящего обозначения для получивших преимущественное использование качественных методов, он предпочтет именовать проделанную работу «обследованием ("enquete”)» [7, с. III-IV], определив с помощью французского слова, обозначающего и анкету, и опрос, основанный на прямом взаимодействии с людьми способ получения данных для аналитической составляющей своих исследований.

Желая как можно более точно методологически идентифицировать и свои, и широко практиковавшиеся земской статистикой в целом «обследования», увлекшийся проблемами теории и методологии статистики А. А. Кауфман, отнесет их к анкетному опросу - одному из способов исследования, не соответствующих строгим требованиям сплошного массового статистического наблюдения, хотя и не выходящих за его рамки. Организованная по земскому типу русская статистика крестьянского хозяйства предельно раздвинула последние (в том числе и усилиями самого А. А. Кауфмана) за счет включения в арсенал статистики не нашедших себе иного пристанища качественных методов анализа «этнографической экономики».

Составляемые земскими статистиками поселенные (пообщинные) описания, с помощью которых, помимо прочего, добывались сведения о формах общинного землевладения и землепользования, он сочтет методологически близкими «чистому типу» анкеты, регистрирующей не факты экономической действительности, но «субъективные мнения и впечатления» о них. И, словно чувствуя инородность рассматриваемых качественных приемов исследования основному телу статистики, уточнит: «Это, конечно, не статистика в тесном смысле этого слова, но все же в... анкете есть и известный элемент массового исследования: при таких 2016. T. 17, № 4. C. $699-720$ 
анкетах... собирается значительное число показаний, а массовое мнение компетентных людей также носит признаки массового наблюдения, в значительной мере устраняя влияние случайных взглядов и случайных ошибок отдельных лиц» [5, с. 445].

Невзирая на отмеченный факт фиксации в ходе поселенных опросов преимущественно нечисловых данных, инкорпорация анкетного исследования в число статистических методов изучения общественных явлений заставит А. А. Кауфмана (в учебнике) сделать акцент на возможностях «числовой разработки» описательного материала, носящего массовый характер, и проигнорировать приемы, позволяющие исследовать неподдающиеся количественному анализу аспекты социальной реальности. В связи с чем, упомянуты будут не собственные работы, а «объективные научно-статистические» исследования К. Р. Качоровского, подвергшие статистической обработке сведения о формах землепользования в России, в которых «каждое селение рассматривается как единичный случай, и эти единичные случаи группируются и подсчитываются по тем или другим, характеризующим случаи и интересующим исследователя, признакам» [5, с. 446] .

Ссылаясь на существование слишком уж различных толкований слова «анкета», А. А. Кауфман предпочел впоследствии заменить «обследование ("enquete”)» своей первой работы на несущий несколько иную смысловую нагрузку «экспедиционный путь (способ)» наблюдения. Чем подчеркнул и исследовательский характер интервью - направленность на исследователя, а не на опрашиваемых крестьян вопросов программы, и играемую последними пассивную роль

${ }^{6}$ К. Р. Качоровский полагал «путем массового, статистического исследования, так как оно представляет единственный способ научно-точного познания в области социальных явлений» [8, с. 27] выяснить причины существования различных форм крестьянского землепользования, установить законы их эволюции, которые подскажут будущее общинной организации. 
«объекта» обследования. Но, главное, - нацеленность на получение от «экспертов» достоверных сведений, объективных данных о формах землепользования, о тех социальных практиках, посредством которых они реализуются, а не субъективных о них «впечатлений» ${ }^{\text {. }}$ Хотя последние, призванные продемонстрировать ясное представление крестьянами тех или иных процессов, происходящих в области землепользования, и представленные наиболее яркими, колоритными выдержками из записанных бесед с ними, и присутствуют на страницах его работ ${ }^{8}$

В заблуждение не должно вводить стремление привлечь к участию в интервью («беседе») наиболее толковых, сведущих и откровенных, насколько это продемонстрировал подворный опрос, крестьян (каковых «может не найтись ни одного не только на целую деревню, но даже на целый район» [5, с. 450]). Получаемая от них информация также должна была

7 Стоит подчеркнуть, что методология «этнографической экономики» не была, конечно же, направлена на установление форм поземельных отношений и выявление причин, обусловливающих их становление и развитие, посредством толкования смыслов, придаваемых своим действиям самими участниками этих отношений: такие действия рассматривались как порождаемые внешними по отношению к участникам силами окружающей среды. Другими словами, это не была столь популярная сегодня «экономика слов», широко использующая в своих целях и этнометодологию.

${ }^{8}$ В своей работе «Формы крестьянского землевладения в Московской губернии» В. И. Орлов предпринял интересную и целенаправленную попытку «уяснить отношения самих крестьян к общинной форме землевладения», с целью чего крестьянским сходам и отдельным крестьянам задавался вопрос: «не стеснительно ли для хозяйства мирское землевладение с его переделами и дроблением полос, и если стеснительно, то не лучше бы было, если бы общественная земля была поделена на подворно-наследственные участки?». При этом постановка вопроса сопровождалась разъяснением «темных» и «светлых» сторон обеих форм землевладения. Автор не только обнародовал наиболее «типичные» высказывания крестьян, но обобщил их, указав на обусловленность «воззрений крестьян» как «хозяйственным положением» общин, так и «имущественным состоянием» Дворов опрошенных [13, с. 274-276].

2016. T. 17, № 4. С. 699-720 
подвергаться проверке и исправлению, как и в случае с «показаниями», даваемыми в ходе подворной переписи, призванной доставить преимущественно количественные данные. Более того, «определенно-направленный интерес» исследователя к выяснению «более тонких признаков» земельно-общинных форм, возлагал именно на него обязанность не просто «поставить каждый вопрос удобопонятным образом», но и принять самое активное участие в процессе выработки ответов [5, с. 446; 4, с. 69] ${ }^{9}$.

Однако даже использование вопросов, носящих «инквизиториальный характер», далеко не всегда приводило к желаемому результату и позволяло добиться описания или объяснения повседневных и естественных для крестьян действий, тем более относящихся к недавнему прошлому, являющихся, хотя и «свежими», но уже воспоминаниями. Указание на «экспедиционный метод», поэтому, не позволяет отождествить его только лишь с «изустным опросом» и делает значимым присутствие исследователя, вооруженного теоретическим опытом, на месте событий и непосредственное наблюдение - «констатирование фактов», интересующих его с точки зрения целей и задач исследования. Исследователь неоднократно указывал на возможность «воочию наблюдать» процесс перехода от одной фор-

9 Кауфман демонстрирует противоречивость показаний крестьян и настоятельную необходимость их проверки на следующем примере, взятом из практики проведения опроса в Томской губернии: «Вы расспрашиваете сельский сход относительно существующих земельных порядков, - вам дают ответы, дающие полное право заключать о существовании вольного пользования: “у нас земля вольная, - каждый пашет, где глянется”, - “земля общественная - ежели я полосу пашу, а другой возле с сохой станет - как я могу воспрепятствовать?" - "пока я пашу - я хозяин, бросил пахать - земля общественная", и т. п. Но тут же вы узнаете, что добрая половина общественной земли вошла в состав нескольких крупных заимок и совершенно недоступна для массы общинников. Получается, таким образом, как будто бы, явное противоречие...» [2, с. 17]. 
мы землепользования к другой или «осязательно представлять» причины таких переходов, подчеркивая, тем самым, роль наблюдения как способа понимания изучаемых явлений. Не случайно исследовательский подход А. А. Кауфмана нередко именовался оппонентами несколько уничижительно «глазомерным наблюдением», единственным оправданием которого являлась «элементарность», или очевидность, вскрываемых с его помощью «причинозависимостей» в сибирских общинных порядках [8, с. 38].

Важную роль среди источников информации, использовавшихся исследователем, играли в ряде случаев и документальные материалы: литературные источники, материалы съемочных и разграничительных работ (межеваний), официальные документы и т. д. ${ }^{10}$ Но, главным образом - приговоры сельских сходов, решения волостных судов (расправ), а также наиболее «характерные» заявления крестьян, сохранившиеся в делах последних. Не только назревшие перемены в формах пользования различными угодьями стояли за жалобами или тяжбами крестьян, но - само меняющееся народное правосознание, постепенно вырабатывавшее принципы общинного землепользования по мере изменения условий хозяйствования. Использовавшиеся в выдержках, как и «цитаты» из свидетельств опрошенных крестьян, в качестве иллюстраций тех или иных авторских положений в тексте опубликованных материалов, решения волостных судов и иные относящиеся к формам землепользования документы, публиковались и в приложениях к соответствующим их главам.

10 А. А. Кауфман, регулярно подчеркивавший то большое значение, которое имеет для исследователя земельных порядков на окраинах страны ознакомление с документальными материалами, отводил, тем не менее, последним весьма скромное место среди источников информации. Предупреждая исследователей форм землепользования об угрозе стать заложниками «преданий», «народного говора» и «старинных документов», он настаивал на приоритете прямого наблюдения для понимания скрывающихся за ними отношений. 
Как представляется, именно присутствие в арсенале статистической науки приемов и методов качественного изучения экономической реальности станет одной из причин приверженности А. А. Кауфмана «узкому» взгляду на задачи и возможности статистики, ее определения как метода количественного изучения, находящегося на вооружении других наук. Фактически отнеся качественный анализ к инструментам построения «индуктивного умозаключения» и отделив от них методы и приемы «умозаключения статистического», он оказался в оппозиции как к традиционному для того времени рассмотрению последнего в качестве всего лишь иной формы индукции, так и к «новаторскому» взгляду на статистический метод как орудие номографического познания.

Улавливаемые статистикой «цифровые зависимости» выступают не более чем показателями, или «симптомами», лежащих уже не на поверхности, а в глубинных основаниях социальных процессов, каузальных связей. Связей, обусловливающих хозяйственное поведение людей, определяющих тот или иной складывающийся в результате их поведения порядок поземельных отношений в зависимости от действия объективных сил окружающей среды, природной и социальной [6, с. 209-211] ${ }^{11}$. Их выявление дело отнюдь не

${ }^{11}$ Сплошное массовое, или статистическое, наблюдение, полагал А. И. Чупров, «подмечает» или «указывает» на существование причинной связи, в то время как качественная методология «открывает возможность» проникнуть в «природу» последней [24, с. 226]. Следует подчеркнуть, что на исходе XIX столетия отечественная экономическая наука обратила свой взор на качественные исследования в ходе обсуждения вопроса о «монографическом методе» статистического описания, констатировав существование «широкого поля» для качественных наблюдений, «не уловляемых числами», обеспечиваемого поселенными (пообщинными) описаниями земской статистики. При этом, справедливо полагая, что только качественные исследования способны уловить «перемены в народной жизни, крайне важные для общественной науки, а также причинные связи между различными явлениями» [21, с. 96]. 
статистики (статистического метода), а экономической науки. В нашем случае - той самой «этнографической экономики», в результате качественного исследования создающей аналитические обобщения, «индуктивная формула» (цепочка опирающихся на принцип неразрывности причин и следствий рассуждений) которых противоположна вероятностной логике статистики. Не случайно, поэтому, А. А. Кауфман на завершающем этапе своей интеллектуальной биографии, связанном с разработкой проблем теории и методологии статистики, определил свои первые работы как относившиеся к экономике (экономической науке) и носившие характер научных обобщений [1, с. 268].

Процедура построения «индуктивного умозаключения» А. А. Кауфманом, операционально была описана А. А. Чупровым в отзыве на итоговую в области «живой истории общины» его работу - и с опорой на нее - «Русская община в процессе ее зарождения и роста» (1908). В ходе качественного научного исследования ученый, на его взгляд, должен последовательно и «не форсируя темпов работы» осуществить несколько стандартных операций. В результате первой из них надлежало на основе анализа имеющихся в его распоряжении первичных данных «неточных наблюдений» и сопоставления свидетельств (устных и письменных) построить схему «мыслимых реальных отношений», которая представляет собой не что иное, как систему взаимосвязанных понятий (категорий), «сколько-нибудь адекватных изучаемым явлениям», или установить типологию форм крестьянского землепользования.

Вторая операция предусматривала возвратное движение от выработанных понятий к ранее выполненным описаниям «единичных фактов», как с целью пересмотра и переосмысления последних, так и критического переопределения самих понятий (или, добавим, отказа от них и выработки новых, более точно отражающих реальность), а также осуществления «на 2016. T. 17, № 4. C. 699-720 
почве» этих понятий новых «обильных» описаний. На третьем этапе выработанная и уточненная типология должна была использоваться для целей «научной систематизации» результатов наблюдений, выполненных другими исследователями, работающими в данной проблемной области [23, с. 6].

Следующий, и последний, шаг схемы исследовательских операций, выделенный А. А. Чупровым и связанный с использованием выработанной типологии для целей уже исторических реконструкций, противоречил, однако, заявленной А. А. Кауфманом направленности «индуктивного умозаключения» на выявление законов типических явлений. Модель исследовательского процесса в этнографической экономике «по Кауфману», поэтому, на практике включала в качестве, если не завершающей, то еще одной и ключевой операции выявление причинно-следственных связей, обозначающих влияние окружающей среды на развитие способов хозяйственного взаимодействия людей в области землевладения и землепользования и определяющих последовательность смены их форм.

В таком «усечении» исследовательского пути, пройденного А. А. Кауфманом, и ограничение его «описательным» этапом, можно усмотреть критику А. А. Чупровым метода коллеги по экономическому цеху, который, при всех похвалах в адрес содержания и формы рецензируемой работы, он полагал покоящимся лишь на «творческой интуиции» ее автора. Использованное, дабы подчеркнуть недюжинные усилия, потребовавшиеся от ученого для реализации столь масштабного исследовательского проекта, выражение «tour de force», которое, однако, может быть переведено и как «ловкий трюк», следует счесть болезненной реакцией на критические замечания А. А. Кауфмана в адрес защищенной (и опубликованной) в Страсбурге диссертации самого А. А. Чупрова [3]. Посвященная общине и написанная преимущественно на материалах русской земской 
статистики, работа содержала классификацию форм общинного землепользования, в основание которой был положен априорно избранный автором принцип «ограничения прав отдельных участников общинного союза по землепользованию». Будучи получен вне изучения, путем непосредственного наблюдения и интервью («расспросов»), слагающейся общины - только и способного вооружить исследователя представлениями относительно зависимости способа организации поземельных отношений от меняющихся «экономических условий» - и применен безотносительно к ступеням эволюции общинной организации, он автоматически превращал любую классификацию в безжизненную, логическую конструкцию.

Качественная методология земской статистики/«этнографической экономики» практически не обратила на себя внимания современников. Рефлексивные и рецептивные аспекты ее формирования в отечественной экономической науке не заинтересовали и историков русской экономической мысли, «передавших» земскую статистику в «ведение» истории статистики. Насущной задачей, поэтому, является возвращение земской статистики на проблемное поле истории экономической науки с одновременной методологической идентификацией предложенного ею подхода к производству экономической знания, чья актуальность определяется одновременной включенностью в реформистское движение, как в самой экономической науке, так и в ее историографии.

\section{Єписок использованной литературы}

1. Кауфман А. А. Автобиография / А. А. Кауфман // Вестник статистики. - 1921. - № 5-8. - С. 260-274.

2. Кауфман А. А. Застывшая история общины. Очерк развития земельных порядков сибирской общины по данным новейших исследований / А. А. Кауфман // Кауфман А. А. 2016. Т. 17, № 4. С. 699-720 
Сборник статей. Община. Переселение. Статистика. - М. : Изд-е Г. А. Лемана и Б. Д. Плетнева, 1915. - С. 3-25.

3. Кауфман А. А. [Рецензия] / А. А. Кауфман // Народное хозяйство. - 1902. - Кн. 4. - С. 184-189. - Рецензия на KH.: Tschuprow A. Die Feldgemeinschaft. Eine morphologische Untersuchung (Abh. aus d. statist. Seminar zu Strassburg, XVIII). - Strassburg, 1902. - VIII + $304 \mathrm{~s}$.

4. Кауфман А. А. Статистическая наука в России : Теория и методология : 1806-1917 : Историко-критический очерк / А. А. Кауфман. - М. : Центр. стат. упр., 1922. - 218 с.

5. Кауфман А. А. Теория и методы статистики : руководство для учащихся и для лиц, посвящающих себя статистическому труду / А. А. Кауфман ; 2-е изд. - М. : Тип. И. Д. Сытина, 1912. - XXVIII + 632 c.

6. Кауфман А. А. Теория и методы статистики : руководство для учащихся и для лиц, посвящающих себя статистическому труду / А. А. Кауфман ; 3-е изд. - М. : Изд-е Г. А. Лемана и С. И. Сахарова, 1916. - V +601 с.

7. Кауфман А. А. Экономический быт государственных крестьян Ишимского округа Тобольской губернии / А. А. Кауфман. Ч. 1. - СПб. : Тип. В. Безобразова и К, 1889. VIII+498 c. - (Материалы для изучения экономического быта Государственных крестьян и инородцев Западной Сибири. Вып. 3).

8. Качоровский К. Р. Русская община. Возможно ли, желательно ли ее сохранение и развитие? / К. Р. Качоровский. М. : Типо.-лит. Рус. т-ва печат. и издат. дела, 1906. - 362 с.

9. Майдачевский Д. Я. «Живая» и «настоящая» история А. А. Кауфмана / Д. Я. Майдачевский / / Историко-экономические исследования. - 2012. - Т. 13, № 2-3. - С. 103-120.

10. Майдачевский Д. Я. Меняющееся пространство экономической историографии: от «расширенной библиографии» к дисциплинарной истории / Д. Я. Майдачевский. - Иркутск : Изд-во БГУЭП, 2012. - 152 с.

11. Менгер К. Исследование о методах социальных наук и политической экономии в особенности / К. Менгер // Менгер К. Избранные работы. - М. : Издательский дом «Территория будущего», 2005. - С. 287-495.

12. О’Брайен Д. П. Теория и эмпирическое наблюдение / Д. П. О'Брайен // Панорама экономической мысли конца XX столетия / под ред. Д. Гринэуэя, М. Блини, И. Стюарта : в 2 т. / пер. с англ. под ред. В. С. Автономова, С. А. Афонцева. - СПб. : Экон. шк., 2002. - Т. 1. - С. 59-80. 
13. Орлов В. Формы крестьянского землевладения в Московской губернии / В. Орлов. - М. : Типо-литограф. С. В. Гурьянова, 1879. - III + 320, 38 с. - (Крестьянское хозяйство. Вып. 1).

14. Осипов Н. О. Об организации земской статистики / Н. О. Осипов / / Труды Императорского Вольного экономического общества. - 1886. - Т. 3, № 12. - С. 388-427.

15. Резерфорд М. Полевые, тайные и включенные наблюдатели в американской экономике труда : 1900-1930 годы / М. Резерфорд ; пер. с англ. // Terra Economicus. - 2012. T. 10, №. 4. - C. 91-106.

16. Розанваллон П. Утопический капитализм. История идеи рынка / П. Розанваллон ; пер с фр. - М.: Новое литературное обозрение, 2007. - 256 с.

17. Саллинз М. Экономика каменного века / М. Саллинз ; пер. с англ. - М.: ОГИ, 1999. - 296 с.

18. Свавицкий Н. А. Предшественники земских подворных переписей / Н. А. Свавицкий / / Очерки по истории статистики в СССР : сб. второй. - М. : Гос. стат. изд-во, 1957. - С. 16-49.

19. Святловский В. Из истории русской статистической литературы / В. Святловский / / Святловский В. К истории политической экономии и статистики в России : сб. ст. - СПб. : Начала, 1906. - С. 161-200.

20. Синютин М. В. Качественная определенность экономики: онтологическая увертюра к спору экономистов о методе / М. В. Синютин // Журнал социологии и социальной антропологии. - 2012. - Т. 15, № 1. - С. 123-139.

21. Статистическое отделение Московского юридического общества в 1891-92 году / / Сборник правоведения и общественных знаний: Труды Юридического общества, состоящего при Императорском Московском университете, и его статистического отделения. Т. 1. - СПб. : Тип. М. М. Стасюлевича, 1893. - C. 53-97.

22. Цвайнерт Й. История экономической мысли в России. 1805-1905 / Й. Цвайнерт ; пер. с нем. ; под науч. ред. В. С. Автономова. - М. : Изд. дом ГУ ВШЭ, 2007. - 410 с.

23. Чупров А. А. Отзыв о сочинении А.А. Кауфмана «Русская община в процессе ее зарождения и роста» / А. А. Чупров. - М., 1911. - 8 с.

24. Чупров А. И. О монографическом описании отдельных селений как способе дополнения и подновления основных земско-статистических исследований / А. И. Чупров // Чупров А. И. Речи и статьи. Т. 1. - М. : Изд-е М. и С. Сабашниковых, 1909. - С. 225-233. 
25. Barnett V. Economic Observation and Measurement in Russia before 1917: Surveying Typicalities and Sampling Totalities / V. Barnett // Observing the Economy : Historical Perspectives. HOPE Annual Supplement / Maas H., Morgan M. (eds.). Durham : Duke University Press, 2012. - P. 46-70.

26. Barnett V. Observing the pre-revolutionary Russian economy / V. Barnett / / Вестник Санкт-Петербургского университета. Сер. 5. Экономика. - 2015. - Вып. 1. - С. 85-102.

27. Maas H. Observation and Observing in Economics / H. Maas, M. Morgan // Observing the Economy : Historical Perspectives. HOPE Annual Supplement / Maas H., Morgan M. (eds.). - Durham : Duke University Press, 2012. - P. 1-24.

28. Sahlins M. Economic anthropology and anthropological economics / M. Sahlins // Social Science Information. - 1969. Vol. 8, no. 5. - P. 13-33.

\section{Информация об авторе}

Майдачевский Дмитрий Ярославович - кандидат экономических наук, доцент, кафедра истории и международных отношений, Байкальский государственный университет, 664003, г. Иркутск, ул. Ленина, 11, e-mail: maid1960@mail.ru.

\section{Author}

Dmitry Ya. Maidachevsky - Ph.D. in Economics, Associate Professor, Department of the History and International Relations, Baikal State University, 11, Lenin str., Irkutsk, Russian Federation, 664003, e-mail: maid1960@mail.ru.

\section{Библиографическое описание статьи}

Майдачевский Д. Я. Земская статистика как экономика: к истории качественных экономических исследований в России / Д. Я. Майдачевский / / Историко-экономические исследования. - 2016. - Т. 17, № 4. - C. 699-720. - DOI: 10.17150/2308-2588.2016.17(4).699-720.

\section{Reference to article}

Maidachevsky D. Ya. Zemstvo statistics as economics: history of qualitative economic researches in Russia. Istoriko-ekonomicheskie issledovaniya = Journal of Economic History $\mathcal{E}$ History of Economics, 2016, vol. 17, no. 4, pp. 699-720. DOI: 10.17150/23082588.2016.17(4).699-720. (In Russian). 